\title{
Web-based Data Analytics Framework for Well Forecasting and Groundwater Quality
}

Muhammed Sit*1,2, muhammed-sit@uiowa.edu

Richard J. Langel ${ }^{1,3}$, richard-langel@uiowa.edu

Darrin Thompson ${ }^{4,5}$, darrin-thompson-1@uiowa.edu

David M. Cwiertny ${ }^{1,4,6,7}$, david-cwiertny@uiowa.edu

Ibrahim Demir 1,2,7,8,ibrahim-demir@uiowa.edu

* Corresponding Author

100 C. Maxwell Stanley Hydraulics Laboratory Iowa City, Iowa 52242-1585, United States

${ }^{1}$ IIHR Hydroscience and Engineering, University of Iowa, United States

${ }^{2}$ Interdisciplinary Graduate Program in Informatics, University of Iowa, United States

${ }^{3}$ Iowa Geological Survey, University of Iowa, United States

${ }^{4}$ University of Iowa Center for Health Effects of Environmental Contamination, United States

${ }^{5}$ Department of Occupational and Environmental Health, University of Iowa, United States

${ }^{6}$ Public Policy Center, University of Iowa, United States

${ }^{7}$ Department of Civil and Environmental Engineering, University of Iowa, United States

${ }^{8}$ Department of Electrical and Computer Engineering, University of Iowa, United States

This manuscript is an EarthArXiv preprint and has been submitted for possible publication in a peer-reviewed journal. Please note that the manuscript has yet to be formally accepted for publication. Subsequent versions of this manuscript may have slightly different content. If accepted, the final version of this manuscript will be available via the 'Peer-reviewed Publication DOI' link on the right-hand side of this webpage. Please feel free to contact the corresponding author for feedback. 


\begin{abstract}
Groundwater supplies drinking water for over one-third of all Americans. However, with aquifers stressed by overdraft, contamination from land use, and the hydrologic impacts of climate change, identifying reliable sources for new wells is increasingly challenging. Well forecasting is a process in which potential groundwater resources are evaluated for a location of interest. While this process forecasts the depth of each aquifer for a given location, it takes historical groundwater well data from nearby locations into account. Conventionally, well forecasting is done by geological survey professionals by manually analyzing the well data and, that makes the process both time and resource-intensive. This study presents a novel web application that performs well forecasting for any location within the state of Iowa in a matter of seconds utilizing client-side computing instead of expensive professional labor. The web application generates well forecasts by triangulating millions of combinations of historical aquifer depth data of nearby wells stored in a state-level database. The proposed web system also provides water quality information for arsenic, nitrate, and bacteria (total c and fecal coliform) on the same interface with forecasts. The system is open to the public and is aimed to provide a go-to tool for homeowners, well drillers and, authorities to help inform decision-making regarding groundwater well development and water quality monitoring efforts.
\end{abstract}

\title{
Keywords: groundwater wells; web application; aquifer depth prediction
}

\section{1- Introduction}

In the United States, 38\% (National Ground Water Association, Groundwater Facts web page, Last Accessed: August 6, 2020) of the population relies on groundwater for its drinking water supply, either from a public source or an unregulated private well. Groundwater is also a vital resource for agricultural irrigation, livestock maintenance, and industrial operations. Today, many groundwater aquifers are overstressed through increasing demand for scarce water resources, climate change, and contamination from naturally occurring (e.g., arsenic) or anthropogenic contaminants (Famiglietti, 2014; Amini et al., 2008; Nordstrom, 2002; Worrall and Kolpin, 2004; Gardner and Vogel 2005; Bierkens and Wada, 2019). Collectively, these stressors are causing old wells to run dry in some parts of the US (Perrone and Jasechko, 2017) while making it increasingly difficult to identify pristine and reliable groundwater sources for new well development. For example, it is estimated that approximately 500,000 new residential wells are constructed each year (National Ground Water Association, Groundwater Facts web page, Last Accessed, August 6, 2020).

A well forecast is an evaluation of potential groundwater quantity and quality for any given location. The well forecasting process identifies the expected depth and thickness of each aquifer at a location. Additionally, when available, this process can provide information on the anticipated water quality from the aquifer(s). The goal of a well forecast is to provide background information about the local aquifers so that informed decisions about well construction can be made to ensure a safe drinking water supply.

Well contractors, consulting engineers, and homeowners are primary groups that benefit from well forecasting. Well contractors may use the information to determine the depth to set the well casing to prevent contaminated water from entering a well. Consulting engineers can access the information to design safe wells for communities and locate alternative water sources if needed. 
Similarly, homeowners will benefit from the information to estimate the cost of constructing a well.

Well forecasting is a time intensive effort. Currently, to the best of our knowledge, no single system or database stores all the information needed to produce a well forecast. Relevant well information in states are often stored in multiple databases managed by different agencies. Information on aquifer depths, thickness and water quality are stored usually in ArcGIS shapefiles, raster files, and in paper publications. All the information found is analyzed to predict the aquifers and water quality at those locations. The results of the interpretation, or the well forecast, is summarized in a report and sent to the requesting individual.

\section{1- Related Work}

Recent developments in web systems and information technologies provide significant opportunities for environmental studies in large scale data handling, management, analysis and, communication. There has been extensive work within the field of hydrology and environmental science using web-based systems. Web systems are actively incorporated into operational and daily communication workflows as watershed and water quality information systems (Demir and Beck, 2009; Weber et al., 2018), intelligent smart assistants for disasters (Sermet and Demir, 2018, 2019), and virtual and augmented reality applications (Sermet and Demir, 2019, 2020).

Significant improvements in the performance of web systems enabled optimized environmental data processing (Demir and Szczepanek, 2017; Sit et al., 2019), geospatial analysis (Demir et al., 2018; Yildirim and Demir, 2019), and decision support systems with serious gaming (Xu et al., 2020; Carson et al., 2018; Sermet et al., 2020). Voluntary and crowdsourced citizen science approaches on the web enable community modeling efforts (Agliamzanov et al., 2019), environmental monitoring (Sermet et al., 2020) with smartphones, and social media analysis (Sit et al., 2019). Studies on urban water planning (Stewart et al., 2010; Jonoski and Seid, 2016), water quality modeling (Kim et al., 2012), resource management (Zulkafli et al., 2017; BascoCarrera et al., 2017), and flood risk management (Yang and Tsai, 2000; Holz et al., 2006) demonstrate the capabilities of web-based systems for hydrology and water resources. Many international case-studies are presented for water resources management using web systems including applications for Finland (Dubrovin et al., 2006), Romania (Almoradie et al., 2013), and Brazil (Azevedo and Parreiras, 2015).

Many states have online applications that provide information on wells after they are constructed. The Iowa Geological Survey's GeoSam (Iowa Geological Survey, GeoSAM web page, Last Accessed: August 6, 2020), Illinois State Geological Survey's ILWATER (Illinois State Geological Survey, Illinois Water Well (ILWATER) Interactive Map, Last Accessed: August 6, 2020), and the Missouri Department of Natural Resource's Well Installation Online Services (Missouri Department of Natural Resources, Well Installation Online Services, Last Accessed: August 6, 2020) are examples of these sites. However, online applications to predict geology are not available in many states. The North Carolina Dept. of Environmental Quality (NCDEQ) has a system to predict geology, but that system applies only to a specific region of the state. The NCDEQ's Data Map interface (North Carolina Department of Environmental Quality, Ground Water Management Branch Map Interface, Last Accessed: August 6, 2020) predicts geologic aquifers along the coastal plain using two different methods. The first method 
predicts aquifer elevations by contouring the tops of the geologic information based on all known information for that unit. The second method reviews the nearest hydrogeologic borehole interpretations and builds a model of the hydrogeologic units for that location based on three boreholes.

Beyond knowing the appropriate depth at which to drill a new well, it would also be beneficial to predict water quality in the tapped aquifer. While predicting groundwater quality can be difficult, there are a variety of approaches that have been developed toward this goal that leverage data from monitoring wells such as subsurface mapping (Iowa Geological Survey, GeoSAM web page, Last Accessed: August 6, 2020) and predictive tools including neural networks (Banerjee et al., 2011; McKinney and Loucks, 1992), conventional machine learning methods (Arabgol et al., 2016), and transport models (Orban et al., 2010; Yao and Zhu, 2019). In all cases, the availability of water quality monitoring data is necessary, where the amount and location of a particular contaminant can be informative in estimating the likelihood of contamination in an adjacent area for a newly constructed well.

For unregulated private drinking water wells, for which quality data is typically sparse and intermittent, tools that provide any level of a priori assessment of well water quality are limited. As a result, there are few, if any, existing resources that provide access to groundwater quality data associated with private drinking water wells. In this regard, Iowa is unique in that it maintains a relatively large set of private drinking water well quality data through its Private Well Tracking System (PWTS), which is operated and maintained by the Iowa Department of Natural Resources (IDNR). The PWTS was created to house private well data collected, in part, through Iowa's Grants to Counties program, which provides funding each year to assist with testing of well water quality for arsenic, nitrate, and bacteria (total and fecal coliform). These are viewed as high priority threats to the public health of private well users in Iowa as a result of both anthropogenic (e.g., land use) and naturally occurring (e.g., arsenic deposits within aquifers) water quality threats.

In PWTS, there are over 135,000 water quality tests collected since 1901 . In addition to water quality data from Grants to Counties testing, PWTS also contains information pertaining to new well construction permits and driller's logs. Information can be added to PWTS at any time by well contractors and county public health officials with proper credentials. As such, PWTS, which is a relational database that stores this information in over 110 tables, is an ideal data set for integration with well forecasting tools to provide an initial assessment of well water quality at the intended site of well installation.

In this study, a web-based data analytics framework, powered by the aforementioned GeoSAM and PWTS databases, Iowa Well Forecasting System (IWFoS), for groundwater wells and water quality is developed and deployed for operational use by public and professionals. While the framework can present previously constructed wells in an easily understandable interface, it also allows both authorities and the public to get forecasts for wells to be constructed in the future. Our paper is organized as follows; the Methodology section describes the specifics regarding the physical world, study area, characteristics of the region and the data sources, Web Application section presents how the framework is developed by discussing the cyberinfrastructure components, data acquisition, how data analysis is handled, and user interface. We further 
discuss the results from a case study and usage of the framework in the results section, and a summary of the proposed framework and future work in the conclusions section.

\section{2- Methodology}

Iowa's geology (Figure 1) can be generally conceptualized as a series of layers (Prior et al., 2003; Stratigraphic Column of Iowa, 2017). Unconsolidated materials, generally associated with a series of glacial events between 2.6 million and 10,000 years ago, form the upper layers over most of Iowa. These materials are grouped together as Quaternary materials. This grouping includes (youngest to oldest) Pleistocene loess, Pleistocene glacial materials, and buried bedrock valley fill materials. Beneath Quaternary material is layers of consolidated sedimentary rocks, such as sandstone, limestone, dolomite, and shale. These rocks formed in shallow seas, deltas, and rivers, which covered Iowa between 74 and 541 million years ago, and generally dip gently to the southwest. These sedimentary rocks can be grouped by system, and include Cretaceous, Pennsylvanian, Mississippian, Devonian, Silurian, Ordovician, and Cambrian age rocks.

Groundwater is neither evenly distributed across the state nor across the various layers. The composition of the layers and their arrangement beneath the land surface determine if a specific layer will have enough water to supply a well. Groundwater across Iowa generally falls into a series of predictable geologic sequences. These sequences establish the framework of regional aquifers in Iowa. Prior et al. provides an overview of the different regional groundwater aquifers in Iowa. This project focused on the Dakota, Mississippian, Silurian-Devonian, and CambrianOrdovician regional aquifers because they are reasonably consistent in nature and had an ample number of wells penetrating each. A short discussion of each aquifer follows.

The Dakota aquifer is composed of sandstone deposits in the Cretaceous age Dakota Formation. The aquifer is mainly used in the northwest and west-central Iowa. The aquifer's water quality tends to be fair to the poor.

The Mississippian aquifer is composed of limestones and dolomites found in the Mississippian age Pella, St. Louis, Warsaw, Keokuk, Burlington, Gilmore City, and Maynes Creek formations. The aquifer is used mainly in north-central Iowa, where the water quality is generally good. The Silurian-Devonian aquifer is composed of mainly Silurian dolomites belonging to the Gower, Scotch Grove, Hopkinton, Blanding, Tete des Morts, and Mosalem formations and Devonian limestones of the Cedar Valley and Wapsipinicon groups. The aquifer is only absent in the northeast and northwest corners of the state. The water quality is generally good in the eastern and northern parts of Iowa. But the water quality rapidly deteriorates as the aquifer thickens toward the west and southwest. The aquifer is usually described as a single aquifer because the Silurian and Devonian units are composed of similar carbonate rocks that have similar hydrogeologic properties and are hydraulically connected. Areas exist, however, where the Silurian and Devonian units are considered independent of each other. 


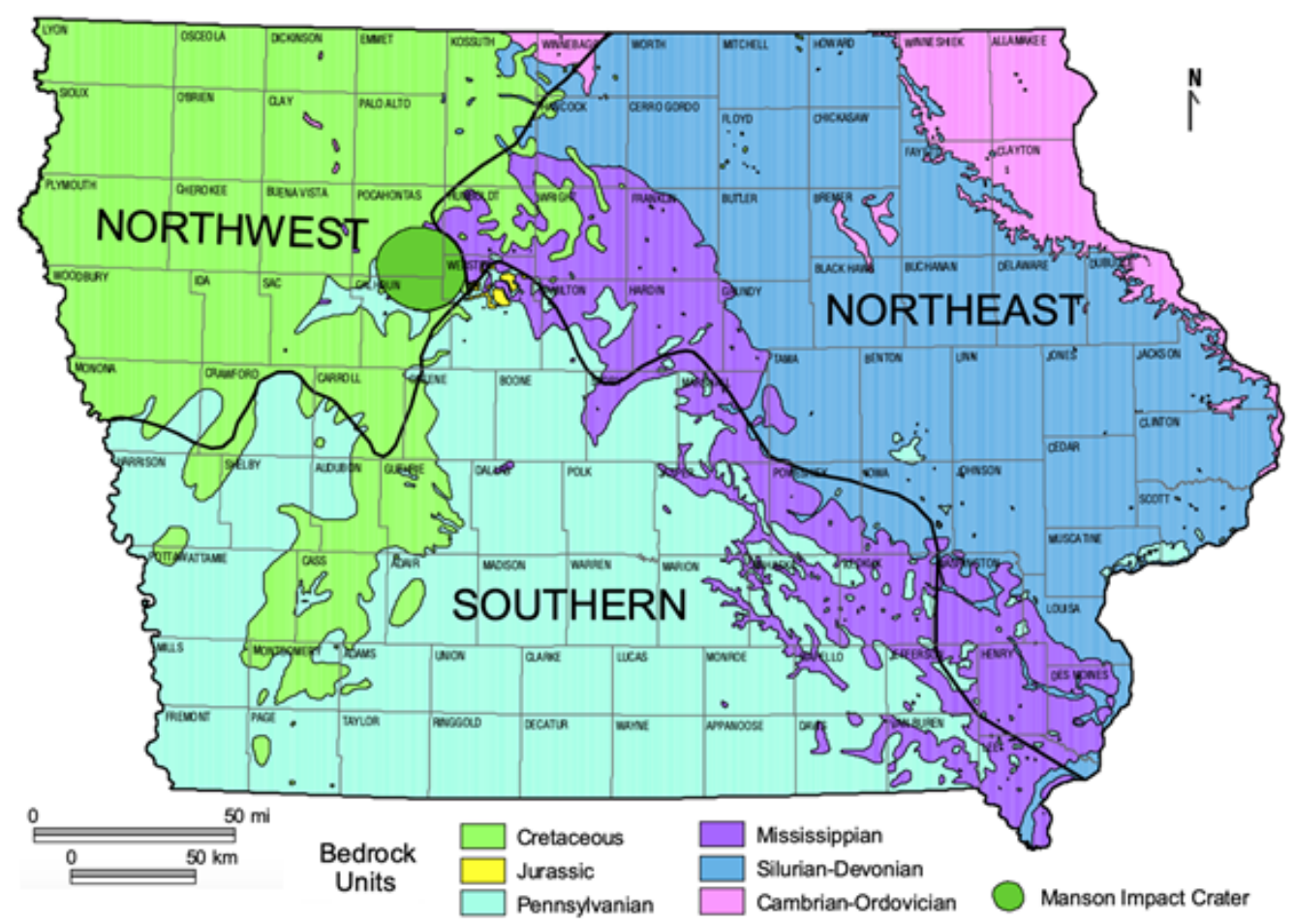

Figure 1. Map of Iowa Geology (Prior et al., 2003)

The Cambrian-Ordovician aquifer consists of the Ordovician age St. Peter Sandstone, Ordovician age sandstones and dolomites of the Prairie du Chien Group, and the Cambrian age Jordan Sandstone. The aquifer covers nearly all of Iowa and is a dependable water source for wells that require large amounts of water. Much of the aquifer's water is derived from the Prairie $\mathrm{du}$ Chien group. The best water quality is found in northeast Iowa, where the aquifer is nearest to the surface. As the depth to the aquifer increases, the dissolved mineral content of the water tends to increase causing the quality to decrease.

A well forecast begins when a landowner, driller, municipality, or other client provides the location of the desired forecast. Every well forecast aims to provide the same basic information; the depth at which bedrock will likely be encountered, the expected depth and thickness of the aquifers at a location, and basic water quality information for each aquifer. No formal procedures exist in Iowa for estimating aquifer depths, aquifer water quality, or reporting the well forecasts. Well forecasts, therefore, may show significant variability related to the geologists who created the forecast.

Well forecasts provided with the Iowa Geological Survey geologist usually access the same resources. Depth to bedrock is estimated using geologic maps and well data. Iowa has an ArcGIS shapefile for the entire state that estimates depth to bedrock to within 50 feet. This coverage provides an initial estimate for the bedrock depth. GeoSam is an Iowa Geological Survey (IGS) site and sample tracking database. GeoSam and PWTS are searched for nearby wells that contain geologic data that may be used to validate or improve the accuracy of the ArcGIS estimate.

Local geology determines which aquifers are potentially available. ArcGIS shapefiles and raster files, publications, and GeoSam are searched for records containing geologic data. These records are used to estimate the depth from the land surface to the top of the aquifer(s) and the thickness 
of the aquifer(s). These estimates have higher uncertainty in areas where geologic data is sparse. Anticipated aquifer water quality is derived from many sources. PWTS well water quality results are widely distributed statewide, but most include only nitrate, arsenic, and bacteria. ArcGIS coverages contain well water quality results that generally include a wide range of chemicals, including analytes like total dissolved solids and sulfate. Unfortunately, these are usually collected from only a few, spatially-limited wells. Paper reports may also contain water quality results. The results of the interpretations and estimations are summarized in a report and sent to the requesting individual. Depending on the requestor's needs, the report may be a simple text email with a summary of the estimations, or a formal report with detailed graphics.

\section{1- Data Sources}

GeoSam database provides location, identification, construction, and geologic information for more than 90,000 Iowa wells. GeoSam is built using a relational database system, MySQL, that utilizes over 100 tables to store and organize data. The principal component of GeoSam is information from water wells constructed over the past century.

Information found on driller's logs, such as well location, construction, geologic materials drilled through, and water depth, is the largest component of GeoSam. Prior to the mid-2000s, well contractors mailed well records to the IGS for manual entry into GeoSam. The introduction of PWTS in the mid-2000s provided more options for submission of driller's logs. Well contractors have the option of entering the driller's log directly into PWTS themselves or submitting the record to the county health department for their entry of the data into PWTS. The IGS has a procedure to then electronically transfer the records from PWTS to GeoSam. Unfortunately, the transfer has only been completed for about $50 \%$ of Iowa counties because the quality assurance procedures are very time-consuming.

GeoSam also contains detailed stratigraphic information from the analyses of well cuttings. Well cuttings are rock fragments that well contractors recover at regular depth intervals while constructing wells. The bulk of the well cuttings the IGS receives are voluntarily collected by drillers, although specific situations exist where cuttings are required by state law. To date, IGS staff have examined well cuttings from 22,377 wells. The geologic units present and the source of groundwater in the wells are recorded as part of this examination, leading to a better understanding of the state's geology and aquifers.

PWTS, which is managed by the Iowa Department of Natural Resources, is designed to collect information about private wells in Iowa. This information includes recording new well construction permits, recording driller's logs, and recording and disseminating well water test results. PWTS is a relational database, built using Microsoft SQL, that stores information in over 110 tables. Information can be added to PWTS at any time by well contractors and county health officials with proper credentials.

A unique dataset in the PWTS is well water test results from private wells. Private well owners are eligible to receive free water tests annually for bacteria, nitrate, and arsenic under Iowa's Grants to Counties program. County health department officials enter these test results into PWTS, where they can be accessed by county officials and the general public. PWTS contains 
information and results from over 135,000 water quality tests. These tests provide a statewide snapshot of nitrate and arsenic concentrations in multiple aquifers.

\section{2- Web Application Development}

IWFoS web application consists of three independent modules, namely the Historical Well Data module, Well Forecasting module and, Water Quality module (Figure 2). Historical Well Data module gathers the previously constructed and reported wells on the GeoSam database for the predetermined geographic boundary around the given county and conveys them to the mainframe of the IWFoS. Water Quality module queries the PWTS database to get previous water quality tests for a predetermined area around the given coordinate pair. Lastly, the Well Forecasting module estimates aquifer depths by taking previously constructed well and aquifer information pulled by the Historical Well Data module into account. While these modules work on both server-side and client-side, the Well Forecasting calculations are made on the client's JavaScript Virtual Machine (VM).

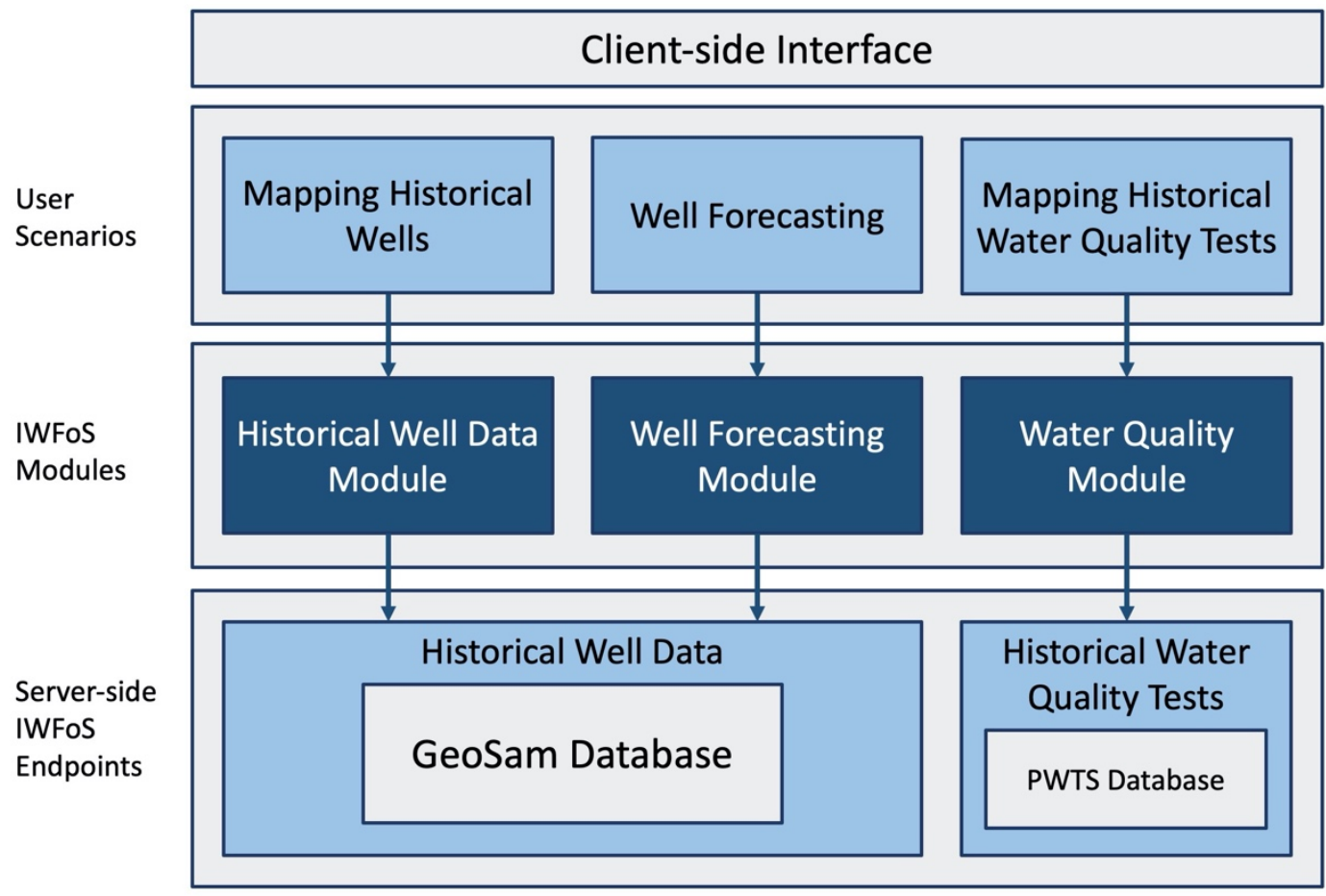

Figure 2. Summary of the modules within IWFoS

The IWFoS runs on a web environment based on PHP 5.4.16 and PostgreSQL 9.2.24 using Apache 2 as the web server. The IWFoS is publicly accessible on the IGS website (https://www.iihr.uiowa.edu/igs/wellforecasting/). The frontend side of the system works on JavaScript. The server-side part of the system is installed on a Red Hat Enterprise Linux (RHEL) 7 running server while client-side experiments and benchmarks were done on an RHEL 7 running desktop computer on Chrome browser.

Users can access the IWFoS features with a map interface powered by Google Maps. This map instance is where counties within the state of Iowa are highlighted, and users are prompted to 
select a county to proceed with the next steps. When the user chooses any county on IWFoS, immediately Historical Well Data Module is initiated for a bounding box covering the selected county with a predetermined buffer zone.

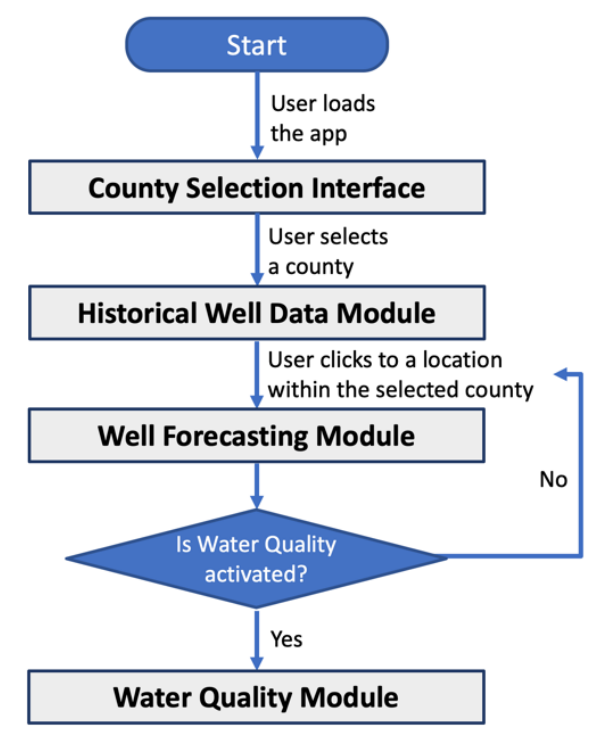

Figure 3. Flowchart of Historical Well Data Module

\subsection{1- Historical Well Data (HWD) Module}

The HWD Module (Figure 3) runs before other modules to connect the historical well database to support most of the functions. It consists of two distinct subcomponents on the client-side and server-side. The server-side subcomponent is initiated when a user selects a county. The serverside HWD subcomponent works with the GeoSam database and gathers the data for previously constructed wells within an area, including the selected county and a predetermined buffer zone. The data contains following columns; well_id, wnumber, bedrock_depth, pwts_id, latitude, longitude, stratigraphy_unit_id, start_depth, end_depth, stratigraphy_penetration_id. Only well_id, wnumber, latitude, and longitude columns are then used by the client-side subcomponent of the HWD Module.

The client-side subcomponent of the HWD module is responsible for mapping all the previously constructed wells on the pre-initiated map interface. Each of the historical wells is used to create their own markers using the longitude and latitude values obtained from the GeoSam database to position them on the map. Aside from the mapping, the HWD module creates an information window for each well and stores the HTML content of each window in the marker instances. By adding a click listener to these markers, users are enabled to interact with wells to obtain well specific information. When a user clicks to any well marker mapped on the interface, the corresponding information box gets rendered by the client-side application. One additional step taken by this subcomponent is the storage of all the necessary data previously acquired from the server-side. An array of wells is, thus, created to store each of the data columns in JavaScript so that they could be used by Well Forecasting Module. 


\subsection{2- Well Forecasting (WF) Module}

The Well Forecasting module (Figure 4) generates forecasts for aquifer depths at which users are likely to encounter water. Since each county has different geological characteristics, number and types of forecasted aquifers change by county, and only aquifers that are represented in that specific county would get forecasted by the module. WF module is activated when a user selects a county and runs when the user clicks on a potential well location on the map. In order to ensure the correct location is conveyed to the WF module, a click event listener from the maps API is implemented. When a location is clicked, the map instance sends the coordinate pair to the client-side well forecasting application, and the application starts making a series of computations over the data previously acquired by the HWD module.

Client-side well forecasting calculations start by validating that the selected point is within the county that was selected on the initial welcoming screen. If the latitude and longitude pair given by the map API doesn't satisfy this pre-requisite for the well forecasting, the system will prompt an error message to the user to ask them to select a point within the selected county. If this requirement is satisfied, the WF module creates a new marker on the initiated map flagging the selected point for a well forecast. After the marker is created on the map, the WF Module then starts using the historical well data acquired in previous steps. The module first measures the Euclidean Distance on earth between each of the acquired historical wells and the selected point. This is done using the latitude and longitude values stored in markers created for each of the wells and the coordinate pair of the selected point given by the click event listener of the maps API. Using the measured distances, the array of the wells stored in the HWD Module is sorted in a fashion where the closest historical well to the selected point becomes the first element in the array.

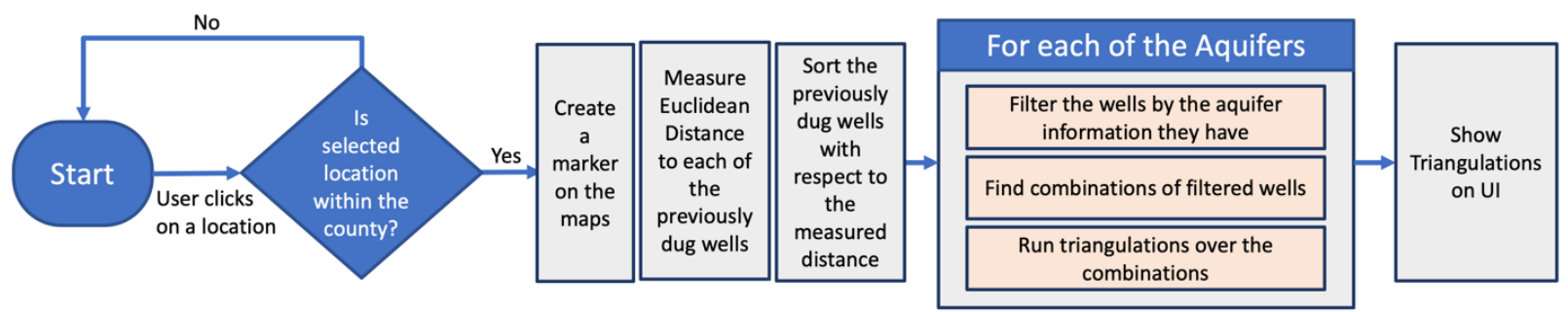

Figure 4. Flowchart of Well Forecasting Module

The sorted array then gets copied for each of the aquifers that exists in the state of Iowa, namely Devonian, Silurian, Cambrian-Ordovician, Mississippian, and Cretaceous. All of these aquifer specific arrays need to be filtered to exclude wells that do not have information regarding the aquifer they are stored in the array. The next step before completing the preprocessing of the wells for the triangulation is finding combinations. 


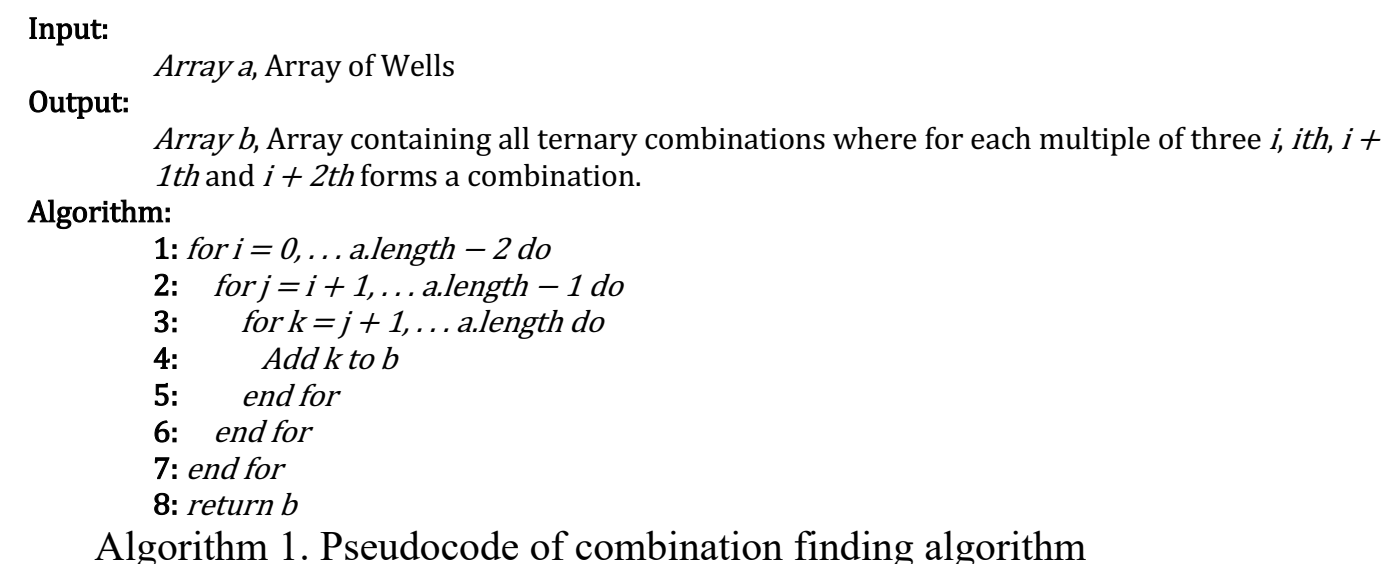

\subsubsection{1- Finding Combinations}

Formulation of the number of combinations to be found can be seen in Equation 1 where $\mathrm{n}$ and $\mathrm{k}$ represent the number of elements in an array and size of each combination, respectively. Finding combinations to triangulate is handled by a client-side function that will find a set of triplets of wells from the array that was sorted in the previous step (Algorithm 1). Finding triplets would not suffice to triangulate for the intended point because not all of the triangles formed by the acquired wells would include the intended point. Thus, the system would need to check whether any of the found combinations would form a triangle that comprises the intended point (Algorithm 2). To overcome this problem, an iterative process is employed.

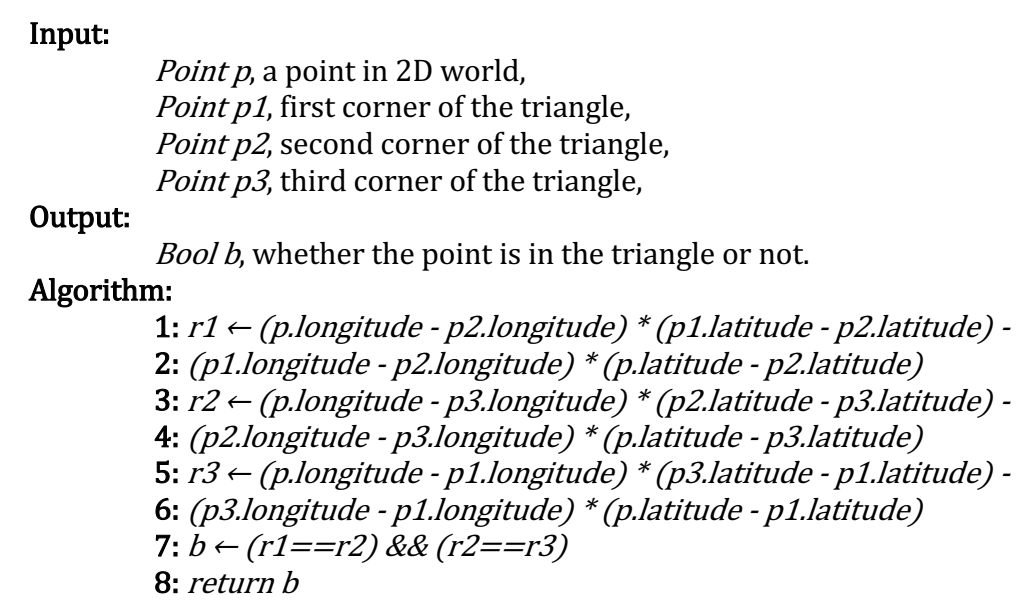

Algorithm 2. Pseudocode of the function that determines whether a point is within a triangle formed by three points

The combination finding function starts by selecting a subset from the beginning of the sorted array; it then forms combinations chosen from this subset and tests them to see if they comprise the requirement. Until the module finds 10 combinations that fulfill the prerequisite of comprising the intended point, the combination finding function runs over the sorted array. If it reaches the end of the subset before finding 10 combinations, it gets an extended subset from the sorted array and continues the process until fulfilling the 10-combination requirement is satisfied. 


$$
\begin{aligned}
& \left(\begin{array}{l}
n \\
k
\end{array}\right)=\frac{n(n-1) \ldots(n-k-1)}{k(k-1) \ldots 1}=\frac{n !}{k !(n-k) !} \\
& W_{p_{1}}=\frac{\left(P_{2_{\text {lon }}}-P_{3_{\text {lon }}}\right) \times\left(P_{\text {lat }}-P_{3_{\text {lat }}}\right)+\left(P_{3_{\text {lat }}}-P_{2_{\text {lat }}}\right) \times\left(P_{\text {lon }}-P_{3_{\text {lon }}}\right)}{\left(P_{2_{\text {lon }}}-P_{3_{\text {lon }}}\right) \times\left(P_{1_{\text {lat }}}-P_{3_{\text {lat }}}\right)+\left(P_{3_{\text {lat }}}-P_{2_{\text {lat }}}\right) \times\left(P_{1_{\text {lon }}}-P_{3_{\text {lon }}}\right)} \\
& W_{p_{2}}=\frac{\left(P_{3_{\text {lon }}}-P_{1_{\text {lon }}}\right) \times\left(P_{\text {lat }}-P_{3_{\text {lat }}}\right)+\left(P_{1_{\text {lat }}}-P_{3_{\text {lat }}}\right) \times\left(P_{\text {lon }}-P_{3_{\text {lon }}}\right)}{\left(P_{2_{\text {lon }}}-P_{3_{\text {lon }}}\right) \times\left(P_{1_{\text {lat }}}-P_{3_{\text {lat }}}\right)+\left(P_{3_{\text {lat }}}-P_{2_{\text {lat }}}\right) \times\left(P_{1_{\text {lon }}}-P_{3_{\text {lon }}}\right)} \\
& W_{p_{3}}=1-W_{p_{2}}-W_{p_{1}}
\end{aligned}
$$

Eq 4.

\subsubsection{2- Triangulating Combinations}

When 10 combinations for each aquifer are found for the given location, they are passed to the triangulation interface of the WF module one by one. Triangulation interface triangulates the start and end of each of the aquifers found in all of the wells that make the triplet. Triangulation for depth values is done using the weight formulations in Equations 2, 3, and 4, which employ the Barycentric coordinate system. The Barycentric coordinate system allows one to find a point's coordinates according to the triangle containing the point itself. Calculating Barycentric coordinates of a point outputs three weights where these weights represent the distance of the selected point to each of the corners of the triangle. Then these weights are multiplied by the depth value contributed by each corner to calculate the triangulation of the selected point. It should be noted that even though the module finds combinations for a specific aquifer, triangulations are made for all the aquifers that the wells forming these combinations have data. An example triangulation after weights are calculated could be found in Figure 5.

When all of the triangulations are completed, they get rendered by the client-side interface to the HTML. This interface creates a new information box in front of the map and shows triangulations (Figure 6). When the forecasting is completed, it renders a bar chart for each of the aquifers found for the selected point. These bar charts show the average of the start and end depths from all 10 triangulations for the specific aquifer. Each of the bar charts is accompanied by a summary text showing the forecasted start and end depths for that aquifer. This information is shown when the user hovers over any of the bar charts. Bar charts are also equipped with a mouseover event listener to expand the information box so that the 10 separate triangulations for any of the aquifers could be seen. These bar charts are made clickable to further investigate individual triangulations. Each of the triangulations within the extension is presented with their own bar charts that show the start and end depths of the aquifer. They are also equipped with mouseover and click listeners to show the detailed triangulation results. Detailed triangulations show the forecasted depth values for each of the aquifers that the wells have data. Also, the mouseover and click listeners of the triangulation bar chart triggers a visualization function that shows the locations of the wells that are used for that triangulation by connecting them with lines on the map forming a triangle. 


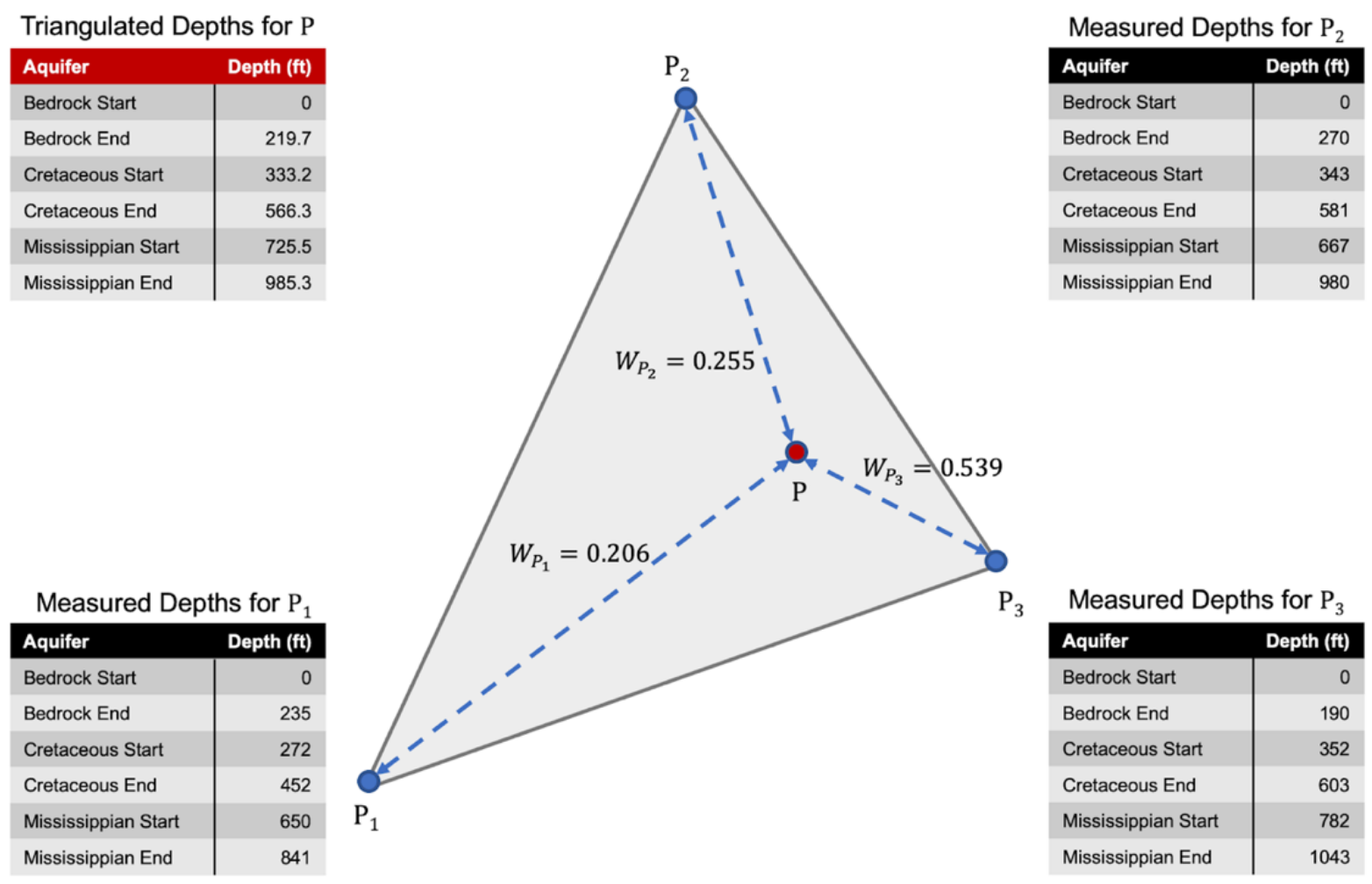

Figure 5. An example of how triangulations were made given the weights from Barycentric Coordinate System

\subsection{3- Water Quality (WQ) Module}

Water Quality Module can be initiated after a well forecast is completed. When a well forecast is completed, the WF module renders an information box on the interface. The information box has a dropdown selector for water quality test types as options, namely, Nitrate, Coliform, Fecal Coliform, and Arsenic. When any of the options are selected from this dropdown selector, the server-side WQ component of the WQ module queries the PWTS database to get water quality test results for the selected water quality test type. This request is made to query a $10 \mathrm{~km} \times 10$ $\mathrm{km}$ area surrounding the point for which the well forecasting is run; thus, it needs to make the request using the coordinates of the selected point.

The server-side WQ component returns a list of water quality tests for the selected contaminant to the client-side. It returns an array of key-value pairs that reports, well_id, latitude, longitude, test_id, test_type, result, is_present, result_designation, result_unit, and date_sampled. Before returning, the array gets reduced to concatenate separate test results throughout the past years for the same well into one item in the result array. This information then used by the client-side rendering subcomponent of the WQ module. This submodule creates markers on the map instance for each of the wells with WQ data reported by the server-side WQ component. It also implements a click event for the markers to show detailed information on the historical water tests. This information is shown on the information box panel with information for individual wells shown on the map by the HWD module (Figure 6). Reported information is structured as a table of water quality tests conducted on selected well throughout history. Furthermore, the data 
shown on the table could be downloaded in CSV format via the "Download Data" button underneath the table. The download button calls an external server-side function within the WQ module that returns the same key-value pairs, but this time for the well_id of the selected well. It should be noted that the table shows up to 5 water quality tests, but the exported data file returns the entire dataset for the selected location.

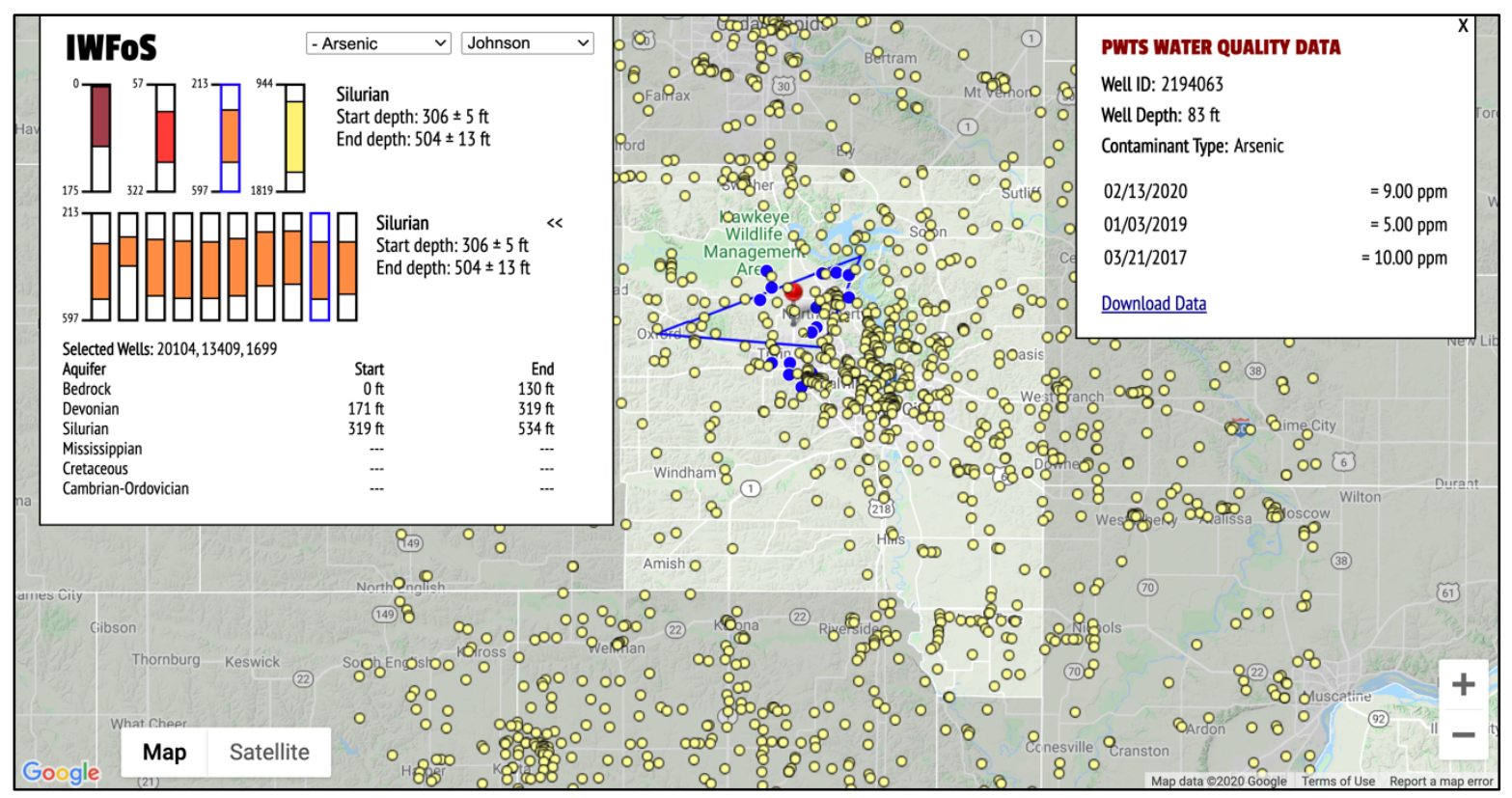

Figure 6. Water Quality results interface along with triangulation results from Well Forecasting Module

\section{3- Potential Use Cases}

IWFoS offers different opportunities for different stakeholders. Well contractors need to know the aquifers and their water quality that exist in specific areas because they impact the job scope and cost. Traditionally, well contractors rely on personal knowledge supplemented with data found in the DNR's PWTS or IGS' GeoSam databases. IWFoS predicts which aquifers and the drilling depths needed to reach those aquifers. IWFoS displays well water quality information in nearby wells that may indicate water quality issues in those aquifers. Thus, IWFoS saves well contractors time because all relevant data is integrated into one location with advanced data exploration and forecasting functions.

Homeowners can receive numerous benefits from IWFoS. For example, they may use IWFoS to verify information provided by well contractors on the projected depth and thickness of aquifers at their home. Homeowners may also use IWFoS to check if there are water quality problems in their vicinity. If there are nearby wells with water quality issues, they may be more likely to test the water quality in their own well. If the homeowner's water quality is problematic, they can compare the costs associated with treating the water to a safe level, versus the cost of drilling a new well to a different aquifer identified using IWFoS.

County health departments may use IWFoS to document aquifers or specific areas in their county with known water quality issues. Homeowners in the impacted areas may be contacted and encouraged to have their water tested. If issues are found, the health department may discuss 
risks and remediation options with the homeowner. If water quality issues are sufficiently documented, the health department may work to amend county ordinances so that wells are not drilled in affected areas. County public health staff can also use IWFoS to improve testing through the Grants to Counties program in Iowa. For example, areas in IWFoS where quality data are limited correspond to portions of counties with well users that have not previously used the program funds for testing. These areas could be a priority for future efforts by public health officials to identify and enroll well users for testing.

\section{3- Case Study \& Results}

The area (Figure 7) near Lake Macbride State Park (Johnson County, Iowa) provides opportunities to demonstrate capabilities of IWFoS. The Devonian, Silurian, and CambrianOrdovician aquifers are present in the area (Wahl et al., 1978). Limestones and dolomites of the Devonian and Silurian aquifers are closest to the ground surface. The water from these aquifers is generally hard and may be susceptible to contamination, for example, high nitrates, where the overlying materials are thin and offer little protection to the aquifer. Arsenic levels exceeding the EPA's drinking water standards have been found in portions of the Silurian aquifer in the area. The Cambrian-Ordovician's sandstones and dolomites lay deep beneath the surface (generally over 1,000 feet below the surface). While this aquifer generally offers good water quality, private and subdivision well generally don't use the aquifer because of the cost associated with drilling a well to that depth.

New wells are being constructed for private houses and subdivisions around Lake Macbride as the area develops. Well forecasts were completed using traditional methods and IWFoS for comparison on the MacBride Estates subdivision, located on the north side of Lake Macbride. The traditional forecast took approximately 3 hours using GeoSam well records, and maps and data found in IGS water atlases and groundwater modeling reports (Wahl et al., 1978; Gannon et al., 2009, 2011). Table 1 shows the results of the forecasts using our traditional process and using IWFoS.

Table 1. Well forecasts generated for the MacBride Estates subdivision. Range reported are feet below the surface. Numbers in parentheses are an expected range.

\begin{tabular}{|l|l|l|l|l|}
\hline & $\begin{array}{l}\text { Unconsolidated } \\
\text { materials }\end{array}$ & Devonian & Silurian & $\begin{array}{l}\text { Cambrian- } \\
\text { Ordovician }\end{array}$ \\
\hline Traditional & $0-\left(70-110^{\prime}\right)$ & $(70-100)-145^{\prime}$ & $145-450^{\prime}$ & $1,005-1,560^{\prime}$ \\
\hline IWFoS & $0-43^{\prime}$ & $43-152^{\prime}$ & $157-421^{\prime}$ & $1,018-1,601^{\prime}$ \\
\hline Completed Well & $0-40^{\prime}$ & $40-150^{\prime}$ & $150-415^{\prime}$ & Not reached \\
\hline
\end{tabular}




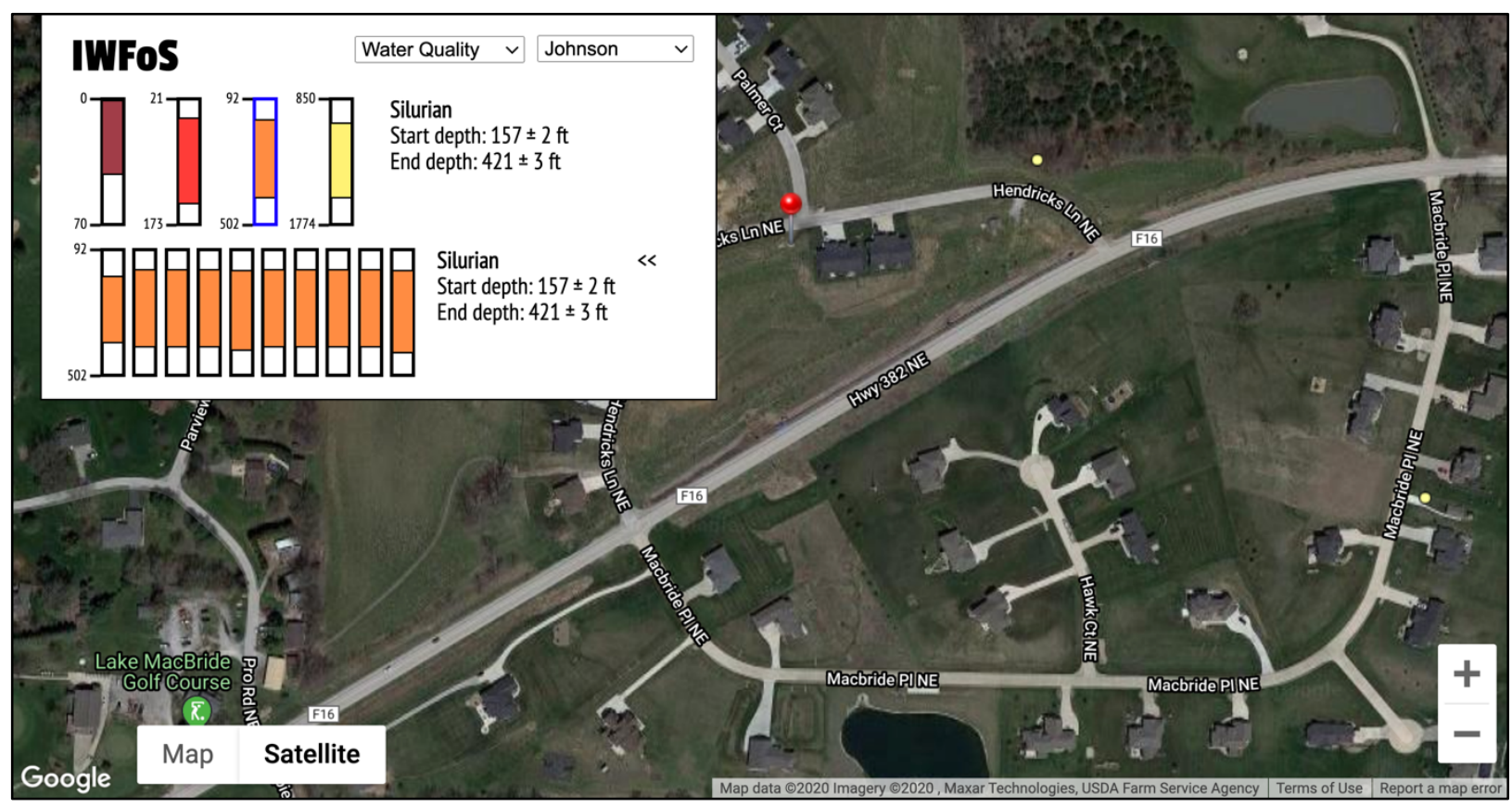

Figure 7. IWFoS Well Forecasting results screen for selected case study location

The completed well forecasting analysis allows a comparison of the forecast to the actual drilled well. Either forecast predicted the actual geology reasonably accurately. However, the speed of the IWFoS forecast is an immediate benefit over a traditional forecast. A traditional forecast takes hours and is dependent on the availability of staff at the IGS. Comparatively, an IWFoS forecast is available $24 / 7$ with a simple click.

Immediate access to the PWTS' water quality data is another benefit of the IWFoS system. Manually searching PWTS for water quality results near a well can add hours to a traditional well forecast. IWFoS provides access to those records with a click. In this area, a user would find that nitrate levels in the area are well below EPA drinking water standards. However, arsenic levels in some nearby wells completed in the Silurian aquifer are twice the EPA standard. Knowing that a well may have unsafe levels of arsenic, a user may make an informed decision on corrective actions (ex. drilling a deeper cost, installing a treatment system, etc.) to ensure a safe drinking water supply.

\section{4- Conclusions}

In this study, we presented a web application to significantly improve the operational challenges of forecasting ground well depth by taking advantage of information from previously constructed wells. This application takes into account millions of potential forecasts and reports the most relevant ones using the coordinates of the selected point and previously constructed wells. While it serves the purpose with high accuracy and provides the information on an intuitive and easy to use user interface, it also does this within seconds so that the process of getting well depth information becomes trivial for both authorities and the public in Iowa. Besides providing the forecasts, the system also provides the historical well information on the same interface in an intuitive way. 
Even though the goal of this study is to provide a web-based system that enables users to forecast well depths easily, the system also serves the purpose of providing reliable water quality information to the public. Using the PWTS database, where years of water quality test results are held and maintained, the water quality tests are presented in IWFoS through an easily understandable user interface. Available water quality data are provided alongside information about the depth of the well from which the water was analyzed. While it remains difficult to accurately forecast private drinking water well quality given the relatively limited availability of data and predictive quality modeling tools for such systems, we contend that providing both water quality information and well depth forecasts in the same interface will enable greater confidence in the well and water obtained through drilling.

Future perspectives for this study include extending the well forecasting and water quality test coverage. Having data with the same structure from nearby states to Iowa could provide better forecast results in border counties of Iowa. Furthermore, when the data from other states get integrated, the same system with the same user interface could be provided to residents of those states. Computational aspects of the system could be improved in future iterations as well. Even though the current state of the web application performs fast enough for its purpose, the system could still benefit from the database-specific query optimization to provide water quality test information faster to its users.

\section{Software Availability}

The application is publicly accessible on Iowa Geological Survey website (https://www.iihr.uiowa.edu/igs/wellforecasting/).

\section{Acknowledgments}

PWTS data is provided by Iowa Department of Natural Resources for annual updates of the database.

\section{Funding}

This research did not receive any specific grant from funding agencies in the public, commercial, or not-for-profit sectors.

\section{References}

1. Agliamzanov, R., Sit, M. and Demir, I., 2020. Hydrology@ Home: a distributed volunteer computing framework for hydrological research and applications. Journal of Hydroinformatics, 22(2), pp.235-248.

2. Almoradie, A., Jonoski, A., Stoica, F., Solomatine, D. and Popescu, I., 2013. Web-based flood information system: case study of Somesul Mare, Romania. Environmental Engineering \& Management Journal (EEMJ), 12(5).

3. Amini, M., Abbaspour, K.C., Berg, M., Winkel, L., Hug, S.J., Hoehn, E., Yang, H. and Johnson, C.A., 2008. Statistical modeling of global geogenic arsenic contamination in groundwater. Environmental science \& technology, 42(10), pp.3669-3675.

4. Arabgol, R., Sartaj, M. and Asghari, K., 2016. Predicting nitrate concentration and its spatial distribution in groundwater resources using support vector machines (SVMs) model. Environmental Modeling \& Assessment, 21(1), pp.71-82.

5. Azevedo, P.C.N., Bastos, G.S. and Parreiras, F.S., 2015, April. A linked open data approach for visualizing flood information: A case study of the Rio Doce Basin in Brazil. 
In 2015 1st International Conference on Geographical Information Systems Theory, Applications and Management (GISTAM)(pp. 1-6). IEEE.

6. Banerjee, P., Singh, V.S., Chatttopadhyay, K., Chandra, P.C. and Singh, B., 2011. Artificial neural network model as a potential alternative for groundwater salinity forecasting. Journal of Hydrology, 398(3-4), pp.212-220.

7. Basco-Carrera, L., Warren, A., van Beek, E., Jonoski, A. and Giardino, A., 2017. Collaborative modelling or participatory modelling? A framework for water resources management. Environmental Modelling \& Software, 91, pp.95-110.

8. Bierkens, M.F. and Wada, Y., 2019. Non-renewable groundwater use and groundwater depletion: a review. Environmental Research Letters, 14(6), p.063002.

9. Carson, A., Windsor, M., Hill, H., Haigh, T., Wall, N., Smith, J., Olsen, R., Bathke, D., Demir, I. and Muste, M., 2018. Serious gaming for participatory planning of multi-hazard mitigation. International journal of river basin management, 16(3), pp.379-391.

10. Demir, I. and Beck, M.B., 2009, April. GWIS: a prototype information system for Georgia watersheds. In Georgia Water Resources Conference: Regional Water Management Opportunities, UGA, Athens, GA, US.

11. Demir, I. and Szczepanek, R., 2017. Optimization of river network representation data models for web-based systems. Earth and Space Science, 4(6), pp.336-347.

12. Demir, I., Yildirim, E., Sermet, Y. and Sit, M.A., 2018. FLOODSS: Iowa flood information system as a generalized flood cyberinfrastructure. International journal of river basin management, 16(3), pp.393-400.

13. Dubrovin, T.A.N.J.A., Keskisarja, V.I.L.L.E., Sane, M.I.K.K.O. and Silander, J.A.R.I., 2006. Flood Management in Finland-introduction of a new information system. Nice, France.

14. Famiglietti, J.S., 2014. The global groundwater crisis. Nature Climate Change, 4(11), pp.945-948.

15. Gannon, J.M., Langel, R., Bunker, B. and Howes, M., 2009. Groundwater Availability Modeling of the Cambrian-Ordovician Aquifer in Iowa, Water Resoruces Investigation Report 2A. Iowa Department of Natural Resources, 2009.

16. Gannon, J.M., Witzke, B. and Langel, R., 2011. Groundwater Availability Modeling, Silurian Aquifer, East-central Iowa, Water Resoruces Investigation Report 5. Iowa Department of Natural Resources, 2011.

17. Gardner, K.K. and Vogel, R.M., 2005. Predicting ground water nitrate concentration from land use. Groundwater, 43(3), pp.343-352.

18. Holz, K.P., Hildebrandt, G. and Weber, L., 2006. Concept for a web-based information system for flood management. Natural hazards, 38(1), pp.121-140.

19. Illinois State Geological Survey, Illinois Water Well (ILWATER) Interactive Map, http://isgs.illinois.edu/ilwater, Last Accessed August 6, 2020.

20. Iowa Geological Survey, GeoSAM, https://www.iihr.uiowa.edu/igs/geosam/, Last Accessed August 6, 2020.

21. Jonoski, A. and Seid, A.H., 2016. Decision support in water resources planning and management: the Nile basin decision support system. In Real-World Decision Support Systems (pp. 199-222). Springer, Cham.

22. Kim, J., Engel, B.A., Park, Y.S., Theller, L., Chaubey, I., Kong, D.S. and Lim, K.J., 2012. Development of web-based load duration curve system for analysis of total 
maximum daily load and water quality characteristics in a waterbody. Journal of Environmental Management, 97, pp.46-55.

23. McKinney, D.C. and Loucks, D.P., 1992. Network design for predicting groundwater contamination. water resources research, 28(1), pp.133-147.

24. Missouri Department of Natural Resources, Well Installation Online Services, https://apps5.mo.gov/mowells/, Last Accessed August 6, 2020.

25. National Ground Water Association, Groundwater Facts, https://www.ngwa.org/what-isgroundwater/About-groundwater/groundwater-facts, Last Accessed August 6, 2020.

26. Nordstrom, D.K., 2002. Worldwide occurrences of arsenic in ground water.

27. North Carolina Department of Environmental Quality, Ground Water Management Branch Map Interface, https://www.ncwater.org/GWMS/openlayers/ol.php, Last Accessed August 6, 2020.

28. Orban, P., Brouyère, S., Batlle-Aguilar, J., Couturier, J., Goderniaux, P., Leroy, M., Maloszewski, P. and Dassargues, A., 2010. Regional transport modelling for nitrate trend assessment and forecasting in a chalk aquifer. Journal of contaminant hydrology, 118(12), pp.79-93.

29. Perrone, D. and Jasechko, S., 2017. Dry groundwater wells in the western United States. Environmental Research Letters, 12(10), p.104002.

30. Prior, J.C., Boekhoff, J.L., Howes, M.R., Libra, R.D., and VanDorpe, P.E., 2003, Iowa's Groundwater Basics, Iowa Geological Survey Educational Series 6, 83 p.

31. Sermet, Y. and Demir, I., 2018. An intelligent system on knowledge generation and communication about flooding. Environmental modelling \& software, 108, pp.51-60.

32. Sermet, Y. and Demir, I., 2019. Flood action VR: a virtual reality framework for disaster awareness and emergency response training. In ACM SIGGRAPH 2019 Posters (pp. 1-2).

33. Sermet, Y. and Demir, I., 2019. Towards an information centric flood ontology for information management and communication. Earth Science Informatics, 12(4), pp.541551.

34. Sermet, Y. and Demir, I., 2020. Virtual and augmented reality applications for environmental science education and training. New Perspectives on Virtual and Augmented Reality: Finding New Ways to Teach in a Transformed Learning Environment.

35. Sermet, Y., Demir, I. and Muste, M., 2020. A serious gaming framework for decision support on hydrological hazards. Science of The Total Environment, p.138895.

36. Sermet, Y., Villanueva, P., Sit, M.A. and Demir, I., 2020. Crowdsourced approaches for stage measurements at ungauged locations using smartphones. Hydrological Sciences Journal, 65(5), pp.813-822.

37. Sit, M., Sermet, Y. and Demir, I., 2019. Optimized watershed delineation library for server-side and client-side web applications. Open Geospatial Data, Software and Standards, 4(1), p.8.

38. Sit, M.A., Koylu, C. and Demir, I., 2019. Identifying disaster-related tweets and their semantic, spatial and temporal context using deep learning, natural language processing and spatial analysis: a case study of Hurricane Irma. International Journal of Digital Earth, 12(11), pp.1205-1229.

39. Stewart, R.A., Willis, R., Giurco, D., Panuwatwanich, K. and Capati, G., 2010. Webbased knowledge management system: linking smart metering to the future of urban water planning. Australian Planner, 47(2), pp.66-74. 
40. Stratigraphic Column of Iowa, 2017, access from http://iihr.uiowa.edu/igs/publications/uploads/2017-07-26_13-07-

19 strat column 2017.pdf, Last Accessed August 6, 2020.

41. Wahl, K.D., Ludvigson, G.A., Ryan, G.L. and Steinkampf, W.C., 1978. Water resources of east-central Iowa, Iowa Geological Survey Water Atlas Number 6, State of Iowa, 1978.

42. Weber, L.J., Muste, M., Bradley, A.A., Amado, A.A., Demir, I., Drake, C.W., Krajewski, W.F., Loeser, T.J., Politano, M.S., Shea, B.R. and Thomas, N.W., 2018. The Iowa Watersheds Project: Iowa's prototype for engaging communities and professionals in watershed hazard mitigation. International journal of river basin management, 16(3), pp.315-328.

43. Worrall, F. and Kolpin, D.W., 2004. Aquifer vulnerability to pesticide pollutioncombining soil, land-use and aquifer properties with molecular descriptors. Journal of Hydrology, 293(1-4), pp.191-204.

44. Xu, H., Windsor, M., Muste, M. and Demir, I., 2020. A web-based decision support system for collaborative mitigation of multiple water-related hazards using serious gaming. Journal of Environmental Management, 255, p.109887.

45. Yang, C.R. and Tsai, C.T., 2000. Development of a GIS-Based Flood Information System for Floodplain Modeling and Damage Calculation 1. JAWRA Journal of the American Water Resources Association, 36(3), pp.567-577.

46. Yao, L. and Zhu, Y., 2019. A new forecasting model for groundwater quality based on short time series monitoring data. E\&ES, 227(6), p.062014.

47. Yildirim, E. and Demir, I., 2019. An integrated web framework for HAZUS-MH flood loss estimation analysis. Natural Hazards, 99(1), pp.275-286.

48. Zulkafli, Z., Perez, K., Vitolo, C., Buytaert, W., Karpouzoglou, T., Dewulf, A., De Bievre, B., Clark, J., Hannah, D.M. and Shaheed, S., 2017. User-driven design of decision support systems for polycentric environmental resources management. Environmental Modelling \& Software, 88, pp.58-73. 